\title{
A Festschrift in honor of Philippe Clerc: an eminent and multitalented lichenologist in Switzerland
}

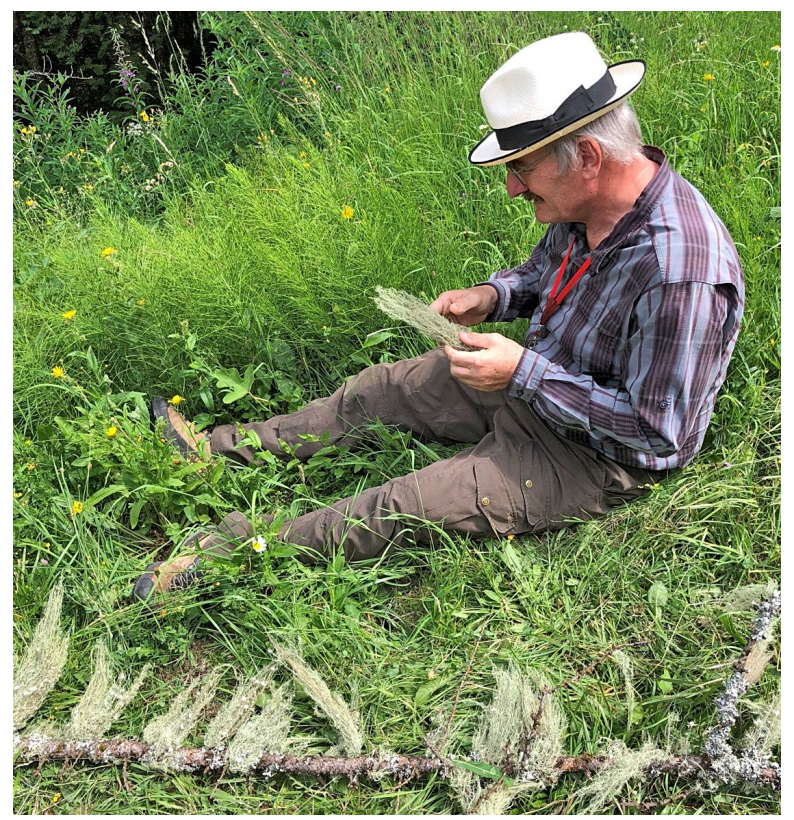

Philippe Clerc with his preferred lichen in the Allandon vallon, Switzerland. Photo taken by Yoshihito Ohmura in 2019

This special issue of Plant and Fungal Systematics is dedicated to Philippe Clerc on the occasion of his retirement from the Conservatoire et Jardin botaniques in the city of Geneva in April. Over the course of his distinguished career, Philippe has devoted his time to elucidating systematics of lichen-forming fungi, their ecology and conservation, and to teaching and outreach. Philippe was born in April 26, 1955 in Lausanne, Switzerland. He obtained his master's degree in Biology (studies about the fluorine effects in the lichen flora) in 1979 and his $\mathrm{PhD}$ (on the genus Usnea, Parmeliaceae in Europe) in 1986 under the supervision of Klaus Ammann. He was a pioneer in the study of lichen photosymbiodemes (undertaken at Duke University) and the use of molecular tools in the classification of lichens. He worked in the Conservatoire et Jardin botaniques de la ville de Genève from 1993-2020. He published about 96 scientific papers, primarily on the systematics of Usnea worldwide, as well as on lichens from the Alps and other areas, often in collaboration with other lichenologists. Philippe supervised many students. He undertook several collecting expeditions, mainly on the American and European continents, and to some Atlantic islands. Philippe also contributed to scientific public outreach, advocating for the herbarium, lichens and nature in general. He also wrote many popular papers. Philippe is an outstanding systematics professional. With about 1.5 million cryptogam specimens alone, the Geneva herbarium is one of the largest and most important herbaria in the world. Philippe worked hard to make it readily accessible to scientists.

We thank all the authors for their contributions to this issue, which is published to express our heartfelt appreciation of Philippe's work.

\section{Alice Gerlach \\ Conservatoire et Jardin botaniques de la Ville de Genève, Genève, Switzerland}

Gintaras Kantvilas

Tasmanian Herbarium, Tasmanian Museum \& Art Gallery, Tasmania, Australia

María de los Angeles Herrera Campos

Instituto de Biología, Universidad Nacional Autónoma de México, Ciudad de México, Mexico

\section{Camille Truong}

Instituto de Biología, Universidad Nacional Autónoma de México, Ciudad de México, Mexico

\section{Adam Flakus}

W. Szafer Institute of Botany, Polish Academy of Sciences, Kraków, Poland

Jolanta Miadlikowska

Department of Biology, Duke University, Durham NC, USA 